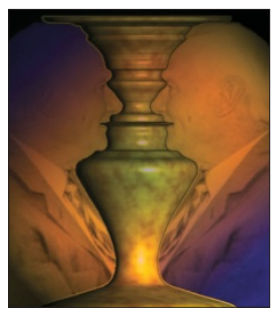

\title{
Francis Crick 1916-2004
}

\author{
Nikos K Logothetis
}

"Don't worry, Ducky. There will be plenty left for you to find out," a mother reassured her ten-year-old son. Fascinated by science, he had one overwhelming fear: that by the time he grew up, everything would have been discovered. "Ducky" was Francis Harry Compton Crick, and there was indeed plenty left. He devoted his life to 'finding out,' cracking the secret of DNA's helical structure and function and later turning his attention to the biological foundations of consciousness. Crick's inquisitive mind was stopped only by his death on July 28, 2004, after a long battle with cancer.

Francis Crick was born near Northampton, England, on June 8, 1916. Even as a boy, he was curious-and enterprising. At about 12, after devouring a student textbook on chemistry, he attempted to make artificial silk and experimented with blowing up bottles filled with explosives and immersed in a pail of water. In 1937, Crick graduated in physics and mathematics from University College London. His initial research activities were interrupted in 1939 by World War II, during which he designed magnetic and acoustic mines.

Only after the war did Crick seriously consider a career in research. His friends did not always facilitate the decision-making process. Some thought he might be better at scientific journalism than in research. His close friend Georg Kreisel, a distinguished mathematical logician, pronounced dryly on his scientific aspirations, "I've known a lot of people more stupid than you who've made a success of it!" "Encouraged by his advice," Crick remembered later, "my next problem was to decide what subject to choose." Even then he was fascinated by neurobiology and molecular biology. His decision to begin with molecular biology was purely based on his scientific background: at the time (1947), Crick was over 30 and knew no biology and practically no organic chemistry or crystallography.

On the advice of Nobel laureate A.V. Hill, Crick moved to Cambridge to work with Arthur Hughes, studying the cytoplasm of chick fibroblasts in tissue culture. The project was of no interest to him but yielded his first two publications. Most importantly, however, during that period, Crick began to form his own ideas about the molecular structure of genes, speculating that they might be made at least partly of DNA, and that the most useful thing a gene could do would be to direct the synthesis of a protein.

In 1949, Crick became a graduate student at a new unit established at the Cavendish Laboratory in Cambridge to study the structure of proteins using X-ray crystallography. It was headed by Max Perutz, under the direction of the brilliant physicist and Nobel laureate Sir Lawrence Bragg, who in 1913 had developed the law of X-ray diffraction. Crick's approach - in my own memories so typical for himwas to first seek to grasp the theory by a combination of imagery and logic, and only later to slog through the algebraic details. He soon gave his first talk on crystallography, entitled "What Mad Pursuit," to the leading lights of crystallography, including its founder Bragg himself.

The author is at the Max-Planck-Institut für biologische Kybernetik,

Spemannstrasse 38, Tübingen 72076, Germany.

e-mail: nikos.logothetis@tuebingen.mpg.de
Crick proceeded to suggest that according to his analysis, only one of the methods they were pursuing had a chance of success: isomorphous replacement. X-ray spots represent the Fourier amplitude spectrum only; the phase is lost. The trick behind isomorphous replacement is to recover phase information by replacing water molecules with heavy metals without perturbing the form of large polymers such as proteins. Crick's prediction turned out to be correct.

During this period, Crick was divorced from his first wife, Doreen Dodd, with whom he had a son, Michael Crick, a freelance computer programmer. He married Odile Speed, an artist, whom he had met while at the Admiralty headquarters at Whitehall where she was a naval officer translating captured German documents. In Cambridge, Francis and Odile had their two daughters, Gabrielle and Jacqueline.

While he was at the Cavendish, Crick met the American James Watson, who in 1951 was only 23 and already had his doctorate. Watson was in Cambridge to help John Kendrew crystallize myoglobin. Crick and Watson hit it off immediately, spending hours talking about proteins, genes and models of DNA. Watson, already a brilliant experimentalist, was very knowledgeable about bacterial genetics. Crick, on the other hand, was primarily working on protein structures and trying to write his thesis. He eventually obtained his doctorate in 1954 on the X-ray diffraction of polypeptides and proteins. Crick and Watson shared the passionate belief that genes hold the secret of protein function, and that solving the structure of DNA was likely to illuminate how proteins obtain their functional form. At the same time, Maurice Wilkins and Rosalind Franklin, of King's College London, were trying to solve the structure with X-ray diffraction photographs of DNA fibers.

Watson and Crick were both enthusiastic about modeling and persistently built one wrong model after the other. Eventually, Crick convinced Watson to try a model in which the phosphate groups were outside the helical structure of the polymer, putting the bases inside the structure, unlike in their previous attempts. This drew their attention to the bases, and before long Watson recognized the significance of the correct base pairs, AT/GC, “.... and suddenly, all the pieces of the chemical jigsaw puzzle had fallen into place and we found ourselves contemplating the DNA double helix," wrote Jim Watson later. "It was so simple, so elegant; that was why it was so exciting and why we were sure even then that it must be right."

The observation was published in Nature on April 25, 1953. The letter concluded with Crick's legendary understatement, "It has not escaped our notice that the specific pairing we have postulated immediately suggests a possible copying mechanism for the genetic material." The diagram of the double helix, the only figure in the paper, was drawn by Crick's wife Odile. Five weeks later the two followed up with another Nature paper that proposed a mechanism for DNA replication. Their decision to write about the significance of their seminal work was based on the support their ideas had received from the $\mathrm{X}$-ray crystallography results of the group at King's College.

In 1962 Crick, Watson and Maurice Wilkins were awarded the Nobel Prize for Medicine. Sadly, Wilkins's colleague Rosalind Franklin (1920-1958), whose excellent experimental work had produced the 
famous helical X-ray picture of the B form that strongly supported the Watson-Crick model, could not be honored. She had succumbed to cancer at the age of 37 .

Crick and Watson subsequently suggested a general theory for the structure of small viruses. Crick proposed that 'information' flows from DNA to protein, but not back again, and Crick and Sydney Brenner in 1961 discovered the triplet genetic code for amino acids.

The names Crick and Watson probably always will be intertwined in many people's minds, but they were distinctively different individuals and would follow different scientific paths in later years. Watson remained in molecular biology, directing the Cold Spring Harbor Laboratory and initiating the Human Genome Project. Crick pursued research in his other field of choice, neuroscience. In 1976, he became Kieckhefer Professor at the Salk Institute for Biological Studies in San Diego, California, where he began his studies of the brain. He would continue this scientific quest until hours before his death.

When I first got to know Crick in the 1980s, we talked about perceptual multistability. He was already deeply interested in the neural correlates of consciousness, and he was fascinated by the appearance and disappearance of patterns during prolonged inspection of the multistable visual stimuli known as puzzle-figures. At first I thought he was interested in consciousness on a general intellectual level, but I soon realized that he had spent considerable time educating himself on neuroanatomy and neurophysiology. He was able to see what was important, what was missing, and which key questions one would need to answer to understand conscious perception. His main tool in exploring his new field was-once again—discussion. He was persistent about getting answers in private or public discussions, and often put speakers on the spot by demanding clear statements about the meaning of their results. He had a unique ability to see the 'signals' through the 'noise' and to organize facts and propose possible hypotheses, many of which still are considered as likely explanations of neurophysiological data.

In one of his first neuroscience publications, a commentary in Nature, Crick and Graeme Mitchison proposed a hypothesis regarding rapid eye movement (REM) sleep, a period marked by rapid bursts of eye movements. REM sleep coincides with periods of dreaming, during which the cortex is vividly stimulated by the brainstem. Crick and Mitchison suggested that "we dream in order to forget." They postulated that the nonspecific stimulation by the brainstem tends to excite cortical neuronal assemblies that are prone to be set off by random noise rather than by highly structured sensory inputs. Such random patterns of activation tend to weaken synaptic connections, which might extinguish thoughts and random associations that are not useful to store. This simple model drew only from the plausible assumption that there are associative neural networks in cortex. Its appeal is that it explains not only the 'unlearning' that might be required in the adult brain, but also the large amounts of REM sleep observed during brain development, where continuous synaptogenesis may generate spurious connections that are likely to degrade the network's performance.

Later, Crick proposed an interesting mechanism to account for psychophysical performance of humans searching for feature conjunctions (say, an object of a certain color and shape among distractor objects). Performance becomes slower as the number of distractors increases, as if one searches serially by moving attention from one location in space to the next. Crick suggested that this 'attentional searchlight' may be mediated by rapid firing of a subset of thalamic neurons, whose excitation is controlled by the thalamic reticular nucleus, a sheet of GABAergic (inhibitory) neurons laterally surrounding the thalamus. This sheet is topographically organized for each sensory modality and it is well placed to influence thalamocortical interactions, because all corticothalamic and thalamocortical axons pass through it, sending excitatory collaterals into the reticular nucleus as they pass. Reticular neurons may hyperpolarize relay neurons in other thalamic nuclei, causing them to fire a short fast burst of spikes (as Rodolfo Llinas reported). This suggested to Crick that the reticular nucleus could increase activity in regions that are activated and further reduce the firing of inactive parts-which could enhance performance in a spatially selective manner.

For the past 15 years, Crick's closest discussion partner has been his much younger colleague and friend, Christof Koch of the California Institute of Technology. Together they have generated many influential-and often provocative-publications presenting appealing and testable hypotheses regarding the minimal neuronal conditions sufficient for one specific conscious percept (for instance, seeing a red ball or having a toothache). They asked what types of neurons give rise to a particular percept, where they are located, where they project to, and what type and strength of thalamocortical connections may be substrates of conscious behavior.

Crick never felt intimidated by the possibility that an experiment could disprove his theories. In fact, he fully expected many of them to turn out to be wrong, just as many of his (and others') initial assumptions about the DNA structure proved to be erroneous. His scientific autobiography, What Mad Pursuit, stressed the importance of intellectual collaboration in helping jolt one out of false assumptions.

Crick was the ultimate reductionist. As a molecular biologist he stated, "Almost all aspects of life are engineered at the molecular level, and without understanding molecules we can only have a very sketchy understanding of life itself. All approaches at higher levels are suspect until confirmed at the molecular level." In a similar vein, writing as a neuroscientist in his Astonishing Hypothesis of 1994, he declared, "It is essential to think in terms of neurons, both their internal components and the intricate and unexpected ways they interact together. Eventually, when we truly understand how the brain works, we may be able to give approximate high-level accounts of our perceptions, our thinking, and our behavior."

Francis Crick is likely to be remembered as one of the most influential biologists ever. Beyond his brilliant, critical mind and his inexhaustible enthusiasm for science, however, Francis-for me and surely for many others-was a dear friend and an irreplaceable discussion partner. As each new scientific result came up, I would find myself wanting to talk it over with Francis. He would immediately appreciate the importance (or insignificance) of the point, he would see and laugh about the pitfalls, he would criticize mercilessly, but he would also think of solutions and come up with suggestions. He was a gentle person, highly considerate of the feelings of others and extremely stoical in the last period of his life.

I was deeply moved by a letter that he sent to me during the most difficult period of his illness: "My Dear Nikos (I drafted this just before you phoned!) I'm eagerly looking forward to your visit next week. My health is still poor. I can concentrate only for short times, but it is hoped that I may improve a little as the after effects of the chemotherapy and the radiation therapy wear off somewhat." He continued immediately with, "My main interest is in a detailed study of the occurrence and especially of the time courses of the responses of the different types of neurons when the monkey is seeing some object or event. ..." And he went on, full of enthusiasm about exploring the claustrum, the strategic structure that receives information from almost all cortex and ostensibly sends the relevant parts back. That was the spirit of the man, whose enthusiasm for 'finding out' never faltered. 